\title{
Topic Study Group No. 54: Semiotics in Mathematics Education
}

\author{
Norma Presmeg, Luis Radford, Gert Kadunz, Luis Puig \\ and Wolff-Michael Roth
}

\section{Aims of the Topical Study Group on Semiotics}

The general aim of TSG 54 at ICME-13 was to explore the significance-for research and practice - of semiotics for understanding issues in the teaching and learning of mathematics at all levels. This aim resulted in a pre-conference Topical Survey (Springer, 2016) that addressed the following aspects:

- Nature of semiotics, and its significance for mathematics education;

- Influential theories of semiotics;

- Applications of semiotics in mathematics education;

- Various types of signs in mathematics education;

- Other dimensions of semiotics in mathematics education.

The four regular sessions of the TSG, and the two sessions of the associated Oral Communications, drew both experienced researchers already using semiotics of various forms in their work, and interested participants who were new to these theoretical orientations. Thus the first regular session (with 48 participants) started with a 10-minute introduction by Presmeg and Radford, in order to summarize the structure of the sessions, and the general nature of semiotic theories (the science of signs), especially as these pertain to mathematics education research.

Co-chairs: Norma Presmeg, Luis Radford.

Team members: Gert Kadunz, Luis Puig, Wolff-Michael Roth.

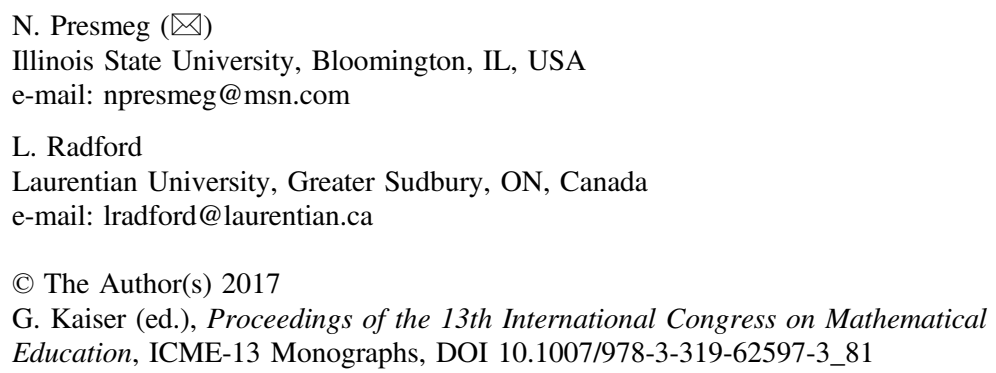




\section{Structure of the Regular 90-Minute Sessions: Day 1}

After the introduction, three plenary papers were presented, as follows:

- Luis Radford: The ethic of semiosis and the classroom constitution of mathematical objects.

- Adalira Sáenz-Ludlow: Geometry examples of diagrammatic reasoning.

- Gert Kadunz: A matter of translation.

Radford explored the production of subjectivities in the mathematics classroom as a semiotic problem. To do so, he discussed an example with pre-school children involved in an arithmetic game. Drawing on the late Vygotsky's semiotics, he focused on the manner in which children, through a vast array of embodied and material signs, position themselves as mathematical subjects and make sense of the mathematics and the rules of the arithmetic game.

Drawing on Peirce's semiotics, Sáenz-Ludlow discussed the concept of diagrammatic reasoning. She argued that diagrammatic reasoning is based on abductive, inductive, and deductive reasoning, leading to a deeper understanding of the objects that signs represent. Then mathematical diagrams appear as epistemological tools that, through systematic observation, can lead the students to better understand the structure and interrelation of mathematical concepts in mathematics problem solving and proving.

Kadunz focused on the nature of mathematical objects. To make his ideas explicit, he organized his considerations on the relation between mathematics in school and at university, and on means of translation between these two realms. He argued that a successful translation does not need the assumption of an objectively existing mathematical instance.

Day 2. Again there were three plenary presentations:

- Wolff-Michael Roth: Birth of signs: From triangular semiotics to communicative fields.

- Candia Morgan: Use of social semiotics to explore institutional assumptions.

- Michael Otte: Semiotics, epistemology, and mathematical generalization.

Roth's paper followed a line of theoretical development of the late Vygotsky, who, near the end of his life, envisioned a radical revision of his work on sign operations. Roth showed that a focus on the developing communicative (semiotic) field that is common to participants gives rise to a fruitful rethinking of traditional approaches to the sign and sign operations.

Morgan's presentation revolved around the general principles and use of social semiotics in mathematics education. Through social semiotic lexical analyses of official documents she pointed out some textual patterns that make visible some assumptions about mathematics, teachers, and students. These patterns configure the kinds of agency that are made available for teachers and students (e.g., students are portrayed as "having needs," and as entities in "need of receiving appropriate support").

Otte's presentation started with an overview of the difficulties that semiotics faced before coming to be seriously considered in mathematics education research in the 
early 2000s. He discussed several key differences between Saussure's and Peirce's semiotics, and, referring to some omnipresent semiotic problems in mathematics (e.g., intension/extension; function/predication, and syntax/semantics), he articulated questions about mathematics generalization from a semiotic viewpoint.

Day 3. The 8 presentations on day 3 were arranged in two parallel sessions. The first 4 of these, with a broad focus on gestures and multimodality, were as follows:

- Ulises Alfonso Salinas and Isaías Miranda: Artifact mediation in the process of objectification.

- Osama Swidan, Naomi Prusak, and Baruch Schwarz: Objectifying the hierarchical classification of quadrilaterals in a synchronic-interactive computer environment.

- Debbie Stott: Gesturing: A key aspect of mediation for young learners in a South African context?

- Alexander Salle and Christina Krause: On the role of gestures for the descriptive analysis of 'Grundvorstellungen': A case of linear functions.

In this session, the theory of knowledge objectification and (artifact, gesture) mediation constituted a common thread. Salinas et al. reported on the role of artifacts and gestures when high school physics students attempted to solve problems concerning the frame of reference when objects moved across an inclined plane. The results show some of the difficulties that students face when trying to make sense of the Cartesian origin, on the one hand, and the mathematics graph as a co-variational concept, on the other. Using the framework of the multimodality of communication, Stott analyzed the gestures that third-grade students in an after-school mathematics club used in the context of solving a mathematics puzzle. Stott's interest was in understanding the subtle semiotic means to which students resort in order to catch other participants' attention. She examined in fine detail the dynamic structures of various semiotic nodes, the multi-modal form of doing/saying, and what is said and what is done. In both studies, artifacts and gestures provided means for knowledge objectification and, thus, for making sense of difficult situations. Guided by the theory of knowledge objectification, Swidan et al. investigated patterns emerging from student investigations of quadrilaterals within the Virtual Math Teams environment. The study illustrates the students' processes of objectification that underpin the production of a hierarchical classification of different types of quadrilaterals. Based on the idea of semiotic bundles, Salle and Krause analyzed gesture-word relations in contexts where students solved problems involving linear relations. Gestures constituted Petra Menz and Nathalie Sinclair objectifications of Grundvorstellungen, basic representations from which mental models are built.

The second parallel session had a broad focus of semiotic chaining and semiotic resources:

- José Francisco Gutiérrez: Exploring tensions in the 'object-subject' dialectic.

- Nejla Gürefe: Analysis of semiotic resources used in process of hearingimpaired students' triangle concept explanation. (Presented in absentia: Turkish presenters could not attend.) 
- Barbara Kinach: Digital visualization tasks for mathematics teacher development: A semiotic chaining analysis.

- Édith Petitfour: Teaching geometry to visual-spatial dyspraxic pupils.

Gutiérrez concentrated on the dialectic of objectification-subjectification when learning mathematics in a social context. He argued that students' semiotic means of objectification sometimes also functions as means of subjectification. In her talk, Kinach observed teacher education through the lens of visualization tasks. She used semiotic chaining as means to analyze innovative visual learning of preservice elementary school teachers. Petitfour presented an approach to the teaching of geometry to students facing difficulties using geometrical instruments with the required precision. She was able to identify and categorize these, and some means of overcoming them.

Day 4. The session started with three presentations, followed by general discussion of issues:

- Petra Menz and Nathalie Sinclair: Diagramming and gesturing during mathematizing.

- Yasmine Abtahi: Semiotic: Signs, tools, and meaning-making.

- Corin Mathews: Division means less: Chains of signification in a South African classroom.

Drawing on new materialism, Menz discussed a classroom episode in which an instructor interacts with a mathematical diagram and makes sense of the mathematics. Abtahi focused on Vygotsky's idea of the ratio object/meaning and its transformation into meaning/object. She illustrated the research question through a mathematical problem in which students resort to concrete materials and the meaning of these objects changes as the classroom activity unfolds. Mathews drew on the idea of chains of signification to show the evolution of the meaning of division in a primary school mathematics classroom.

\section{Oral Communications Associated with TSG 54}

- There were 6 of these, arranged in two sessions.

- Uta Priss: A semiotic-conceptual analysis of conceptual development in learning mathematics.

- José Luis López and José Guzmán: Artifacts and gestures in the process of objectification of the concept of variation.

- Daniela Behrens: Bundling and de-bundling by dragging: From acting to gesturing.

In this session, the three presenters invoked theories of semiotic-conceptual analysis based on Peirce's writings (Priss), objectification based on Radford's work (López \& Guzmán), and semiotic bundling in a study involving gestures (Behrens). A common thread in the papers was students' evolving change in use and conception of notation and other signs in communication. 
- Gloria Inés Sanabria: Translations between semiotic systems.

- Nicole Engelke Infante: Highlighting key links through gesture: A case study of the second derivative test.

- Anna Shvarts: Dual eye-tracking as a method to investigate the acquiring of theoretical perception of visual representations.

Sanabria's presentation featured the problem of translation between semiotic systems from Duval's perspective, invoking discussion about the role of signs and semiotic activity in the production of mathematical objects. Engelke Infante presented a study the goal of which was to determine the effect of the instructor's gestures in the students' understanding of derivatives. Shvarts's presentation dealt with the forms and dynamics of child/adult joint activity through a fine-grained study of perception, oral interventions, and gestures. The use of dual eye-tracking technology facilitated a detailed qualitative analysis of synchronized data. The child not only followed the adult's cultural intervention, but he or she actively coordinated several semiotic registers; understanding appeared to be a result of this coordination at the moments of joint attention at the micro level.

\section{Conclusion}

Following the rich discussion of issues that arose from the presentations, a Springer Monograph is being planned that will allow most of the authors to strengthen and expand their papers in the coming months.

Open Access Except where otherwise noted, this chapter is licensed under a Creative Commons Attribution 4.0 International License. To view a copy of this license, visit http://creativecommons. org/licenses/by/4.0/.

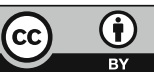

